\title{
REVIEW ARTICLE OPEN Occurrence and public-perceived risk of endocrine disrupting compounds in drinking water
}

\author{
Sze Yee Wee ${ }^{1}$ and Ahmad Zaharin Aris (iD ${ }^{1}$
}

Access to safe water is a crucial factor in determining environmental sustainability, public health, and economic prosperity. Endocrine disrupting compounds (EDCs) are an environmental contaminant of growing concern, which undermine the safety of drinking water. The potential health issues of EDCs are not fully understood yet due to there being relatively scarce research on their exposure and associated risks via drinking water consumption. Because of ineffective drinking water supply systems and unknown risk perceptions of EDCs in drinking water, the role of perceived risks in ensuring access to safe drinking water remains unknown, contributing to the occurrence of such potential risks in the global water system. Integrating preventive measures with a multibarrier approach to safe drinking water is highly challenging because of the relatively low public awareness and political responsibility, as well as the nature and characteristics of EDCs themselves. In addition to reviewing the occurrence and publicperceived risks of EDCs in drinking water, this article focuses on building bases of knowledge and awareness for a better understanding of drinking water quality issues relative to the hazards surrounding EDCs from the perspectives of human exposure and health risk. A conceptual model illustrates the factors that potentially influence risk perception on drinking water quality in regard to not only EDCs but also other issues. Ensuring safe access to drinking water requires interventions that incorporate risk communication and governance, providing insights into political, economic, social, and environmental changes.

npj Clean Water (2019)2:4 ; https://doi.org/10.1038/s41545-018-0029-3

\section{INTRODUCTION}

Safe drinking water safeguards public health, as drinking water is a potential source of human exposure to pollutants. However, the focus has predominantly been on the concerns related to the occurrence of contaminants in the natural environment, and these contaminants have primarily arisen from industrial origin since the beginning of the Industrial Revolution in 1784. Water sources, such as rivers, are a convenient way to dispose of industrial waste, and groundwater is often contaminated via leaching from dumping sites, contributing to waterborne diseases. The occurrence of emerging organic contaminants, particularly endocrine disrupting compounds (EDCs) in drinking water, was resurrected as a major concern in the mid-1970s after the first mention in 1965, yet there were few studies after the mid-1970s. ${ }^{1}$ Scientific efforts were focused on other environmental contaminants such as heavy metals (e.g., lead, which is regarded as the oldest global contaminant) before the potential environmental impacts of EDCs as contaminants emerged as a widespread concern. Currently, the impacts of most commonly known pollutants and newly added pollutants are not well understood, and their effects on the ecosystem and human health are particularly unclear. Meanwhile, most of the studies that have been reported thus far are case studies on the presence and risk of EDCs in aquatic systems and treatment plants (wastewater and water). ${ }^{2-5}$

Currently, occasional legislative and policy enactments in countries throughout the world have demonstrated the challenges related to achieving water security to ensure better quality and healthier lives, regardless of their development level. The number of water and health-related issues is expected to increase due to ongoing natural disasters (extreme events triggered by global warming phenomena) and anthropogenic hazards (oil spills and discharge under industrial as well as domestic activities) (Fig. 1). The subsequent potential outbreaks of waterborne diseases and the increasing number and occurrence of emerging organic contaminants challenge the regulatory agencies responsible for the creation of legislation and policies. Concurrently, regulatory efforts are only required to ensure and maintain the good health and well-being of residents in regard to a safe drinking water supply. Unlike tap water, processed bottled water has been commonly regulated as food, such as in the European Communities (Hygiene of foodstuffs) Regulations and the United States (US) Federal Food, Drug, and Cosmetic Act. With the adoption of sustainable development goals by the United Nations, most countries have become committed to providing a safe drinking water supply, thereby safeguarding public health for all by 2030 . In the contexts of safely managed drinking water and sanitation services, the quality of a drinking water supply that is free from priority chemical contamination forms part of the concern. Additionally, the United States Environmental Protection Agency (US EPA) has published a list of priority drinking water contaminants for regulatory consideration. The Contaminant Candidate List includes endocrine disruptors such as pesticides and pharmaceuticals (veterinary and human).

Despite the challenges in determining environmental EDCs at trace concentrations, multiclass EDCs have increasingly been monitored in widespread locations worldwide (Fig. 2) ${ }^{6-9}$ A variety of EDCs have been observed in the treated drinking water supply throughout the world, particularly in tap water from as low as

\footnotetext{
${ }^{1}$ Department of Environmental Sciences, Faculty of Environmental Studies, Universiti Putra Malaysia, 43400 UPM Serdang, Selangor, Malaysia
} Correspondence: Ahmad Zaharin. Aris (zaharin@upm.edu.my)

Received: 16 July 2018 Accepted: 22 November 2018

Published online: 06 February 2019 


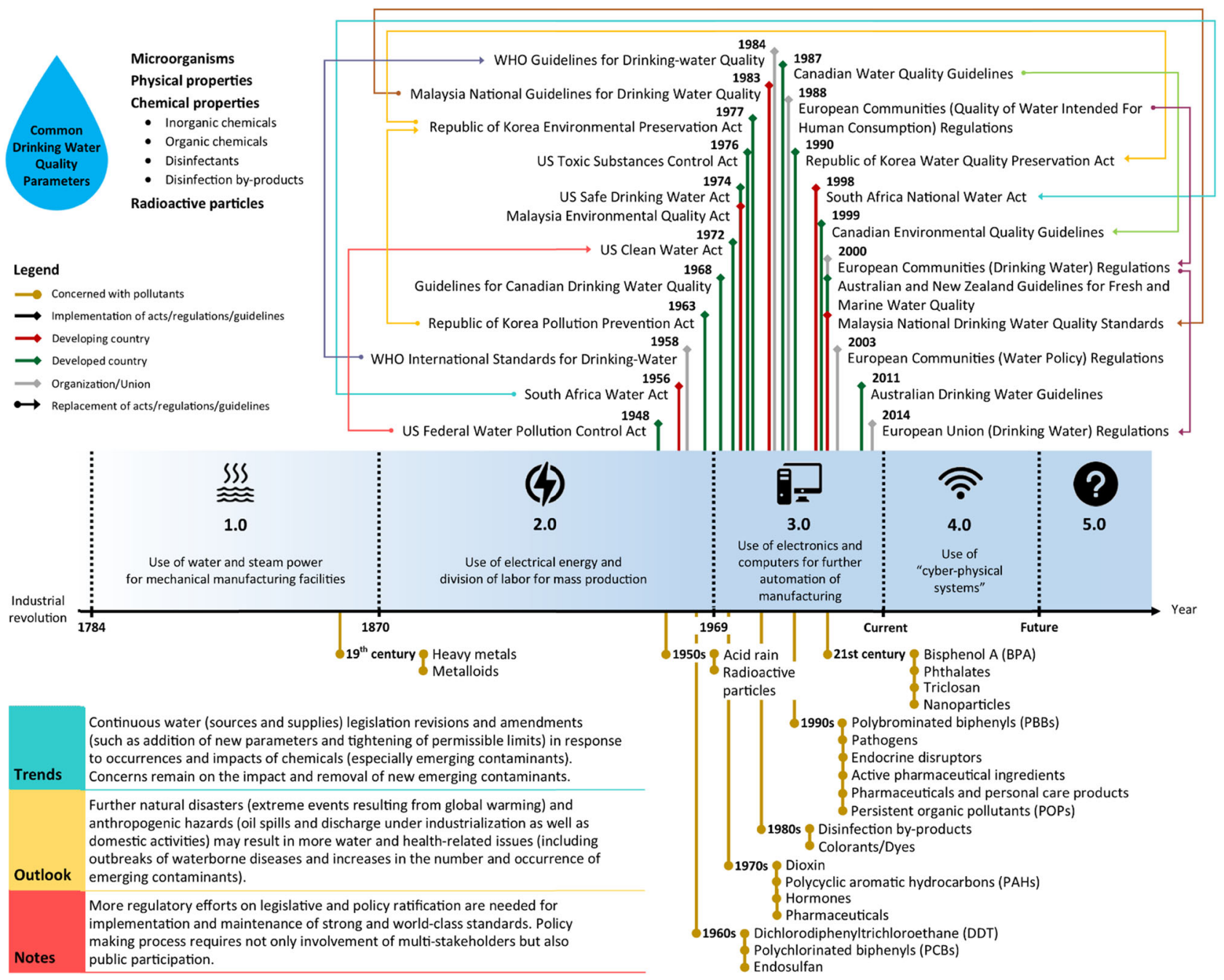

Fig. 1 Chronology of a major emerging concerns related to water pollution and $\mathbf{b}$ new and changes in water legislation in relation to industrialization. Based on the existing drinking water regulations, the commonly regulated drinking water quality parameters are inadequate based on the current exposure levels to EDCs in drinking water. Therefore, regulatory efforts are only required to ensure and maintain the good health and well-being of residents in regard to a safe drinking water supply. Icons courtesy of Freepik (http://www.freepik.com)

$0.2 \mathrm{ng} / \mathrm{L}$ to as high as $5510.0 \mathrm{ng} / \mathrm{L}$, while a maximum concentration $(28,000.0 \mathrm{ng} / \mathrm{L})$ was observed in drinking water from the wells in India. Apparently, this relatively incomplete removal has been due to the broad behaviors of varying EDC loadings, and even advanced treatments and remediation may have been ineffective. Thus, the public is inadvertently exposed to EDCs via drinking water consumption; moreover, the associated risks may have been underestimated and unknown and remain to be investigated. The risk of exposure to inorganic contaminants, such as heavy metals and arsenic in drinking water, is predominantly given high priority, especially in many developing countries. ${ }^{10-12}$ Nevertheless, it is not a common international practice to regulate or provide guidelines for EDCs in drinking water, indicating that there are knowledge gaps and undervalued perspectives on the potential occurrence of EDCs in drinking water and the health risks associated with EDCs via drinking water consumption. The growing concern regarding EDCs is limited to their environmental risks and occupational health and safety risks, whereas the perceived risks of EDC exposure via drinking water consumption remain unknown.

A review of the existing drinking water regulations revealed that the commonly regulated drinking water quality parameters include microorganisms, radioactive particles, physical properties, and chemical contents (e.g., inorganic chemicals, organic chemicals, disinfectants, and disinfection byproducts) (Fig. 1). Organic pollutants, such as pesticides, petroleum products, and solvents, have been greatly explored and developed. Nonetheless, the World Health Organization (WHO) has revealed that the WHO guidelines for drinking-water quality are inadequate based on the current exposure levels to EDCs in drinking water. ${ }^{13}$ Comparatively, the current databases (i.e., monitoring data, treatment processes, metabolism, and associated risks) and regulations (usage and/or manufacturing controls, discharge and/or disposal practices, environmental quality standards, and drinking water regulatory compliance) of emerging EDCs may be inadequate for governing and mitigating EDCs to protect the environment and ensure access to safe drinking water.

The lack of databases represents a knowledge gap that is pertinent to the involvement of the public and government in regulating emerging EDCs. Currently, the relatively low public awareness of and political responsibility for (i) water source protection, (ii) water supply security, (iii) risk assessment (environmental and health), (iii) treatment efficiency, and (iv) future prediction are challenges for the creation of legislation and policies related to a safe drinking water supply. ${ }^{6}$ This challenge is clearly observable when the public risk perception and actual drinking water quality are inconsistent, and the association is instead skewed. ${ }^{14}$ In the context of improving risk governance and 


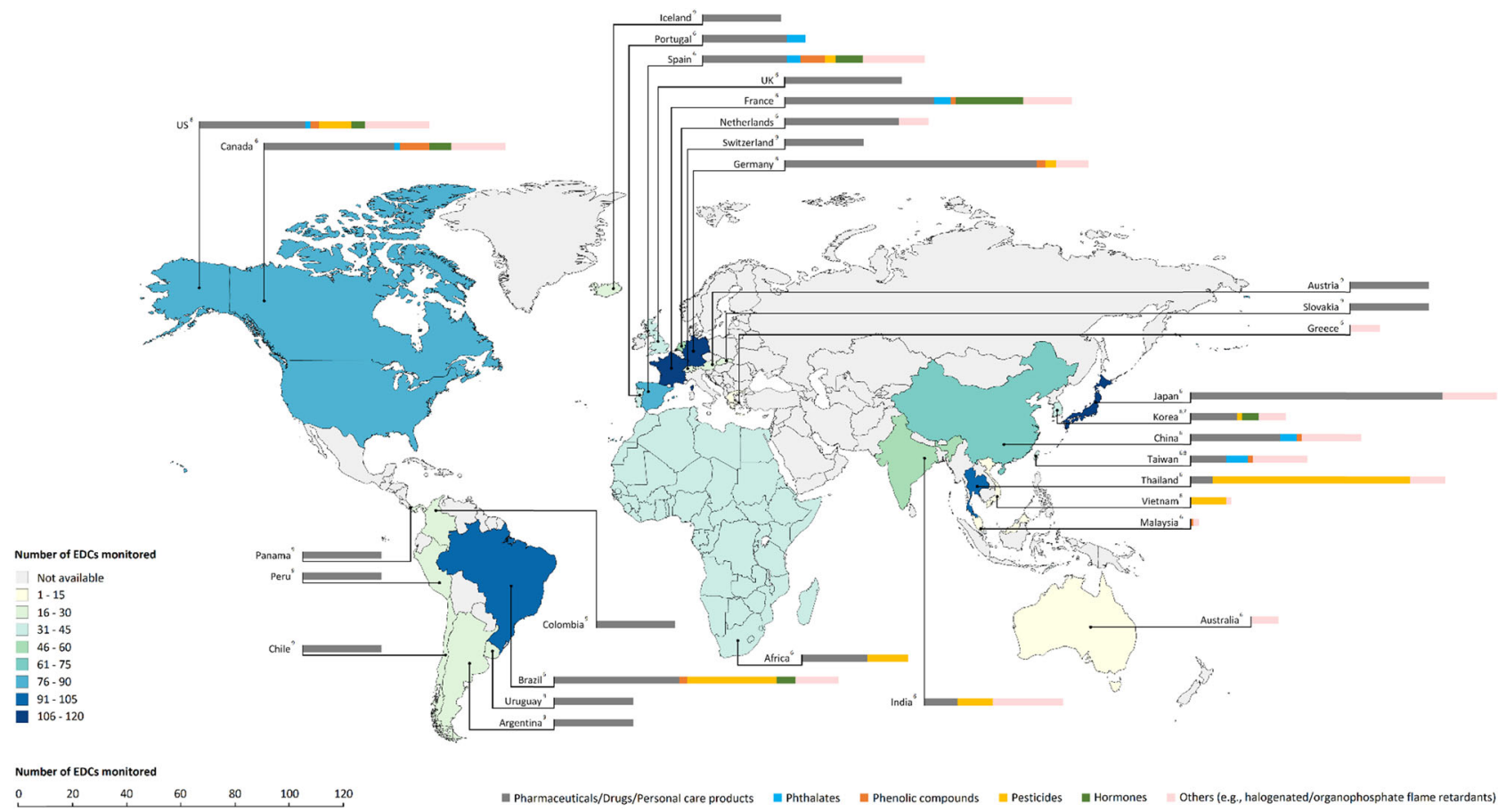

Fig. 2 Countries that monitor EDCs in the drinking water supply. Global EDC monitoring revealed multiclass EDCs in the treated drinking water supply, particularly in tap water, in the range of $0.2 \mathrm{ng} / \mathrm{L}$ to $5510.0 \mathrm{ng} / \mathrm{L}$. A maximum concentration $(28,000.0 \mathrm{ng} / \mathrm{L})$ was observed in drinking water directly from the wells in India. Map created using data taken from refs ${ }^{6-9}$ copyright (Elsevier 2017, 2016, 2014, and 2011). Base map courtesy of mapchart.net (http://www.mapchart.net)

communication, public improvement is the most effective measure to create awareness of risk behavior. ${ }^{15}$ Moreover, risk perception has a potential mediating influence on the development of risk behavior (e.g., preparedness, reduction, prevention, and mitigation). For example, the willingness to pay for improved drinking water quality and infrastructure is affected by the risk perception of consumers. Despite the individual differences in perceiving a risk, the likelihood of engaging in risk reduction behaviors is positively related to the level of perceived risk. ${ }^{16}$ Thus, this article aims to identify the perception of the risks related to drinking water quality by the public. In addition, this article identifies the potential factors that influence the perception by the population of the risks related to EDCs in drinking water, which is also applicable to other water quality issues. By providing a better understanding of public risk perception in regard to human exposure and health risks, this article is intended to be a supportive tool for risk communication and management.

\section{HUMAN EXPOSURE TO EDCS IN DRINKING WATER}

Currently, EDCs have been observed in bodily fluids such as urine, blood, sweat, and breast milk. ${ }^{17-19}$ EDCs are persistent and are dispersed into the environment through (i) wastewater treatment plant (WWTP) and sewage treatment plant (STP) effluents, (ii) human, livestock and animal excretion, (iii) manufacturing and application (e.g., medicine production and pest control), and (iv) environmental processes such as runoff and infiltration. ${ }^{20,21}$ Although the nature and extent of contact with EDCs have yet to be fully established, an overview of human exposure to EDCs in tap water is depicted in Fig. 3. Recently, diverse contamination patterns for organophosphate flame retardants were observed across the drinking water supply (i.e., tap water, purified water, and bottled water) for Korean populations, and water purifiers were identified as a source of contamination and exposure. ${ }^{7}$

Compared to adults, infants and children are particularly more susceptible to EDC exposure. Because humans in early life stages (infants and children) consume more drinking water on a body weight basis, infants and children could have higher exposure levels than adolescents and adults. ${ }^{22}$ The daily intake of bisphenol A (BPA) via drinking water consumption for infants (1340 ng/day) is nearly ten times that for adults ( $148 \mathrm{ng} /$ day) due to the higher levels of BPA leached from baby bottles compared to those leached from bottled water. ${ }^{23}$ Other susceptible life stages include older adults ( $\geq 65$ years of age) and pregnant and lactating women as their physiological properties change. ${ }^{24}$ In addition, higher water intake rates were observed in pregnant and lactating women compared to control women, as weight gain during pregnancy and milk output during lactation require more water physiologically, contributing to prenatal exposure and impacting fetal development. ${ }^{19,25}$ Subsequently, humans are potentially exposed to EDCs daily, and there are possible health risks associated with drinking water intake.

\section{HEALTH RISKS OF EXPOSURE TO EDCS IN DRINKING WATER}

The presently negligible or low risk of human exposure to EDCs in drinking water should not be neglected. Lifelong water consumption has led to a pharmaceutical exposure level $(<10 \%$ of a daily medical dose), even after the treatment of drinking water reduced the negligible risk by up to $80 \%{ }^{26}$ The effects of human exposure to EDCs have not been fully elucidated to date because of the limited availability of epidemiological studies and experimental toxicology studies. The occurrence of EDCs in tap water is an increasing concern, as health impacts could occur with exposure to EDCs at magnitudes as low as ng/L or less, suggesting the need for a uniform system to investigate human populations with regard to exposure to specific EDCs and the direct health effects. $^{27,28}$ Thus, this concern pertains to the health of humans and the population based on the occurrence of EDCs in the global drinking water supply (Fig. 2). However, the actual risks, i.e., knowledge gaps, urgently need to be evaluated to confirm or disprove the effects of EDCs via drinking water consumption. In 


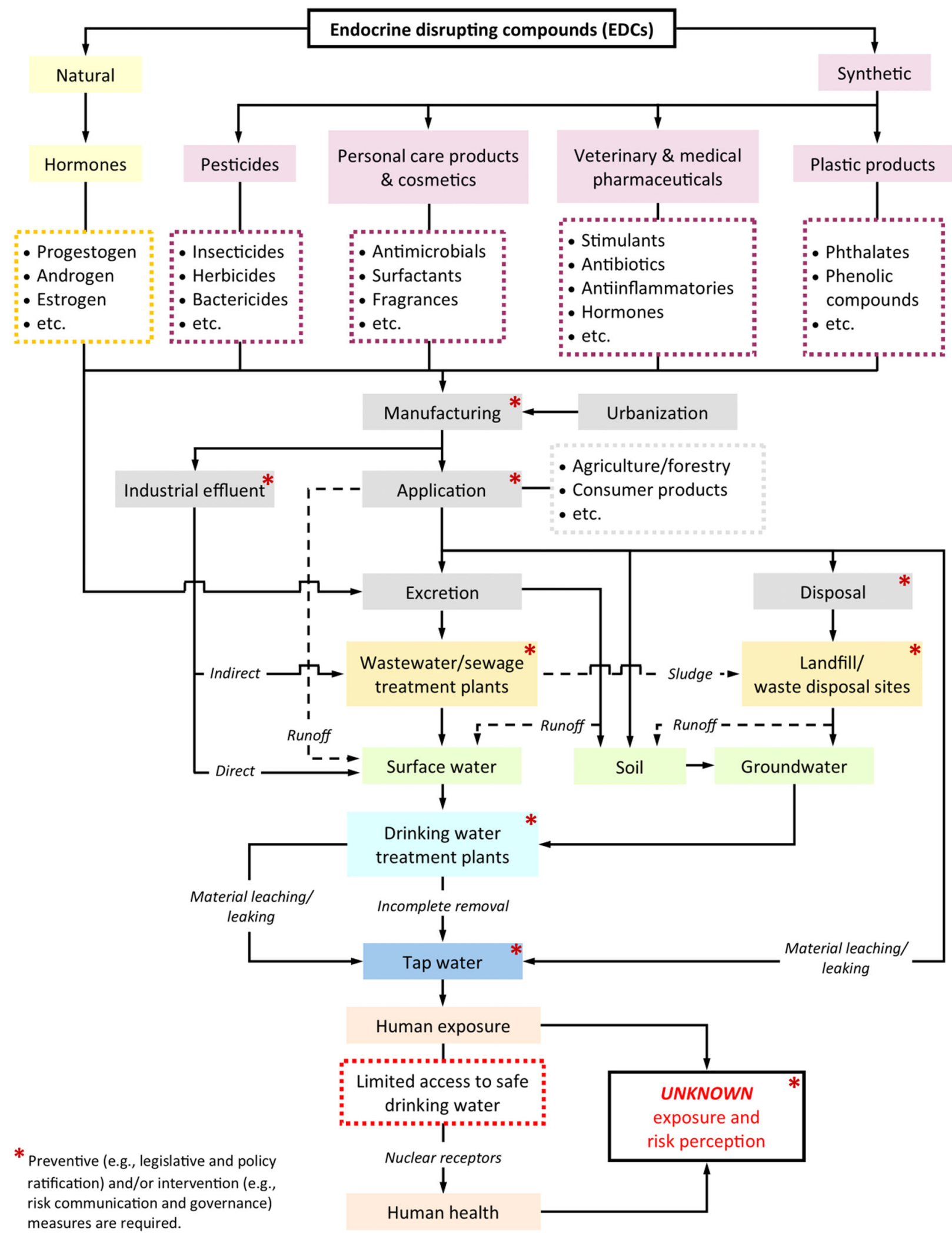

Fig. 3 Overview of human exposure to EDCs in drinking water. Preventive and intervention actions are required to regulate the occurrence of EDCs in the drinking water supply to ensure safe access to drinking water

general, EDCs interfere with the endocrine system, particularly hormone signals, by antagonizing the modes of action and mechanisms of endogenous hormones, especially through nuclear receptors. ${ }^{6}$ The disrupted endocrine system thus causes effects in exposed individuals and populations ranging from acute to chronic diseases, namely, epigenetic deregulation, immune effects, metabolic syndromes, reproductive abnormalities, behavioral changes, disrupted fetal development and growth, 
neurological disorders, and abnormal cell proliferation. ${ }^{27,29-31}$ The consequences depend on several factors, including the age at exposure, exposure duration (both external and internal exposure), exposure magnitude (dosage), and presence of other pollutants. ${ }^{32}$ In particular, the potential hormesis in pollutant exposure, which presents a nonlinear dose-response (low doses stimulate extremely adverse effects, while higher doses have no effect), remains largely unknown. ${ }^{33}$

Due to their higher exposure levels (greater drinking water consumption based on body weight), infants and children have been subject to increased risks that are approximately six times greater than those in adolescents and adults. ${ }^{22}$ Additionally, increased susceptibility has been estimated in pregnant and lactating women compared to control women, and the risk is inherent not only to the mother but also to the fetus or infant. EDC effects are of serious concern, as mortality and fertility rates impact population growth. Meanwhile, more attention should be allocated to the combined effects (additive, synergistic, potentiation, or antagonistic) of EDC mixtures (i.e., parent compounds, metabolites, and other chemical pollutants such as metals) (Table 1), which vary according to the exposure, dose and/or physiological target, although the precise mechanisms have yet to be determined. The interaction and toxicity of parent compounds and byproducts are associated with potential acute and chronic effects, although their occurrence in the water cycle, especially in drinking water, is relatively scarce. The photodegradation products are of less concern in drinking water because of the increasing use and importance of ultraviolet radiation for water disinfection and wastewater purification. Due to the profound risks of EDCs, preventive and intervention actions are required to regulate the occurrence of EDCs in the drinking water supply to ensure access to safe drinking water (Fig. 3).

\section{CURRENT PUBLIC-PERCEIVED RISKS OF EDCS IN DRINKING WATER}

Currently, the perceived risks of EDC exposure via drinking water consumption remain unknown because the increasing interest is limited to the environmental risks and occupational health and safety risks of EDCs. This condition indicates a knowledge gap and undervalued perspectives of the occurrence of EDCs in drinking water and the subsequent detrimental influences on human health via drinking water consumption. The environmental risks and occupational health and safety risks of EDCs have been prioritized in regard to their increased manufacture and usage for a wide variety of applications, such as pesticides, surfactants, fragrances, pharmaceuticals, personal care products, flame retardants, and plasticizers (Fig. 3). To date, studies have mainly focused on risk perception, including (i) policy support (e.g., balancing between application and associated risk), (ii) safety behaviors (e.g., occupational health and safety practices), (iii) handling and disposal practices, and (iv) usage behaviors (e.g., purchase and overuse), influencing factors, and risk responses. ${ }^{34-38}$ Nonetheless, studies have investigated tap water (with and without purifiers), bottled water, desalinated water, recycled water, private water supplies (domestic wells and groundwater), and the factors involved in perceiving and responding to risks (Table 2). Rather than EDC content, studies have typically been limited to the physical properties ( $\mathrm{pH}$ and turbidity), chemical contents (disinfectants, disinfection byproducts, nutrients, metals, and major ions), microbiological parameters (total coliforms and Escherichia coli), and organoleptic/aesthetic properties (taste, odor, and color) of water, while the public has a relatively low level of awareness. Because of the limited monitoring of EDCs in drinking water and the underdevelopment of epidemiological studies on EDCs, the role of the perceived risks in regulating EDC contents in the drinking water supply remains unknown. Moreover, this scarce line of research challenges the adoption of public involvement in the multibarrier approach to the monitoring and management of the drinking water supply system. ${ }^{6}$

Notably, potential inconsistencies and imbalances between the actual and perceived risks are of concern because individual perceptions of risk could play an important role in implementing interventions to ensure safe access to potable drinking water. In a previous study, no association was observed between the perceived and actual quality of drinking water. ${ }^{14}$ However, the communities had different opinions on the water quality from the same water system. Thus, there is a need to evaluate the gap in the risk perception and the causes of effective risk communication strategies, including goals and methods, as well as understandable and scientifically accurate communication materials (e.g., information types and formats). ${ }^{39}$

\section{POTENTIAL FACTORS INFLUENCING THE RISK PERCEPTION OF EDCS IN DRINKING WATER BY THE POPULATION}

The varying risk perceptions depend on the type of risk, risk context, personality of the individual, and social context. ${ }^{15}$ In other words, risk perception can be reflected based on a rational system (i.e., analytical processing system) or a nonrational system (i.e., experiential processing system). ${ }^{39,40}$ The conceptual model of risk perception of environmental EDCs and drinking water quality (Fig. 4) depicts the potential factors that influence the perception of risk by the population of not only EDCs in drinking water but also other water quality issues.

\section{RATIONAL RISK PROCESSING}

Risk matrices, typically including likelihood and consequences, have commonly been used to assess risk characteristics and to rank the risk level. ${ }^{41}$ In a previous study, laypeople perceived risks based on their analytical way of thinking about the probability of occurrence and severity of the consequences, whereas the latter category was found to be the primary determinant for laypeople to perceive risks. ${ }^{39}$ Additionally, contextual factors (i.e., objective characteristics such as cost and convenience) are influential in consumer behavior and decisions. ${ }^{42}$ However, risk characteristics (likelihood of occurrence, potential hazards, etc.) alone are inadequate to explain risk perception. ${ }^{40}$ In contrast, risk perception is often influenced by cognitive and affective variables as much or more than influenced by risk characteristics (Fig. 4). In particular, the rational system has failed to explain the risk perceived in low-risk communities, as individuals use experiential processing (i.e., collective experiences) when perceiving environmental risks. ${ }^{39}$ However, at present, particularly in democratic societies with good education levels and accessibility to riskrelated information, laypeople might tend to process risk differently. Apparently, the contrary point of view requires detailed studies on the public-perceived risks of EDCs in drinking water and the significance of the interrelationship between dimensions of risks to understand the public risk perceptions of human exposure and the associated health risks.

\section{NONRATIONAL RISK PROCESSING}

Individuals' thinking and judgment about the seriousness and acceptability of risks are influenced by various factors, such as knowledge, attitudes, practices, experiences, emotions, and values. An individual's knowledge of the facts is an important determinant, as it may influence his/her judgments and decisions. ${ }^{34,42}$ Here, the misalignment between scientific and public knowledge of risk contributes to public confidence in water quality without regular testing. ${ }^{10}$ For instance, Australian residents clearly discriminated between recycled and desalinated water based on water use, in that desalinated water was generally perceived as preferable for close to body uses, including for 


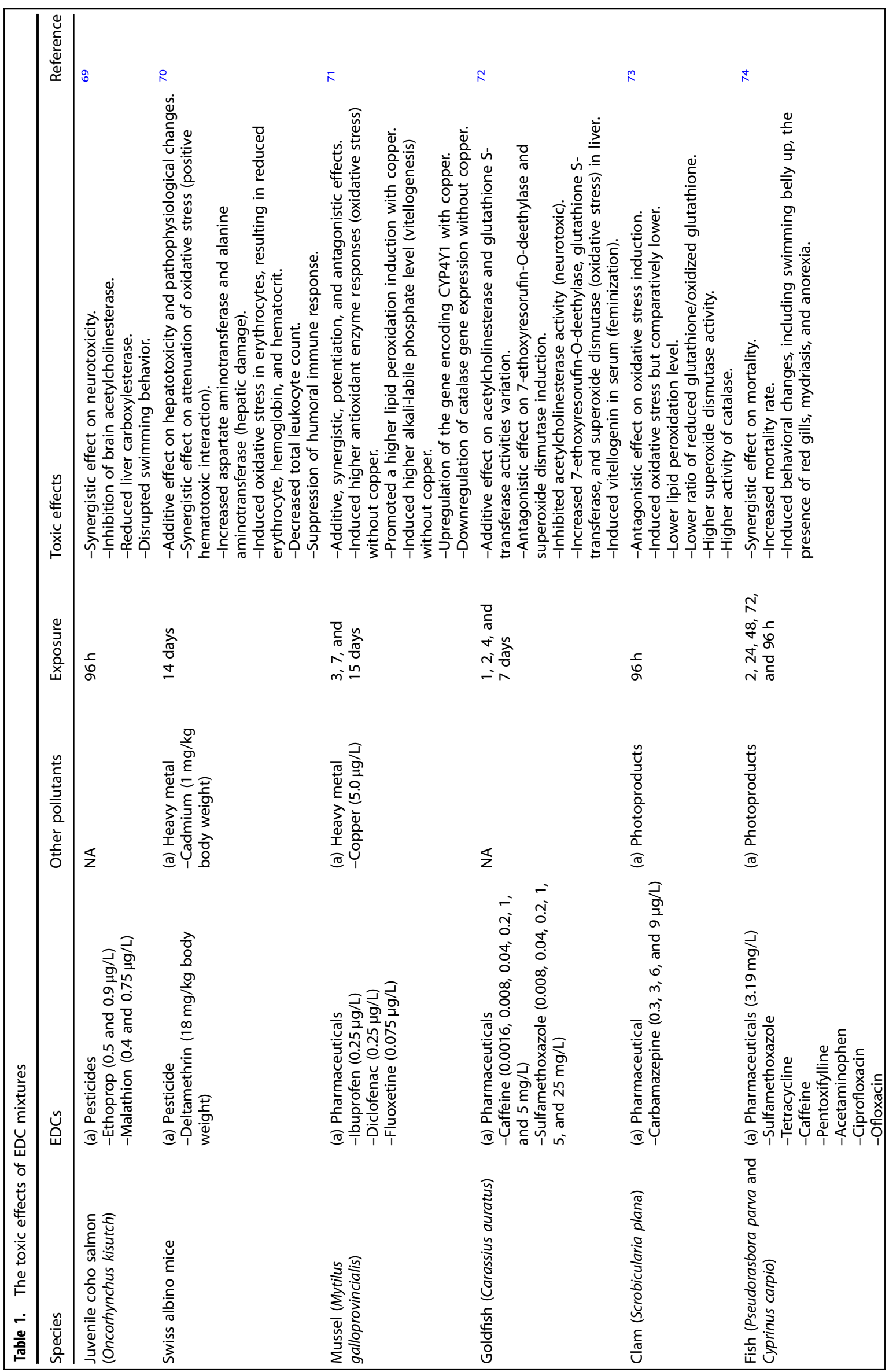




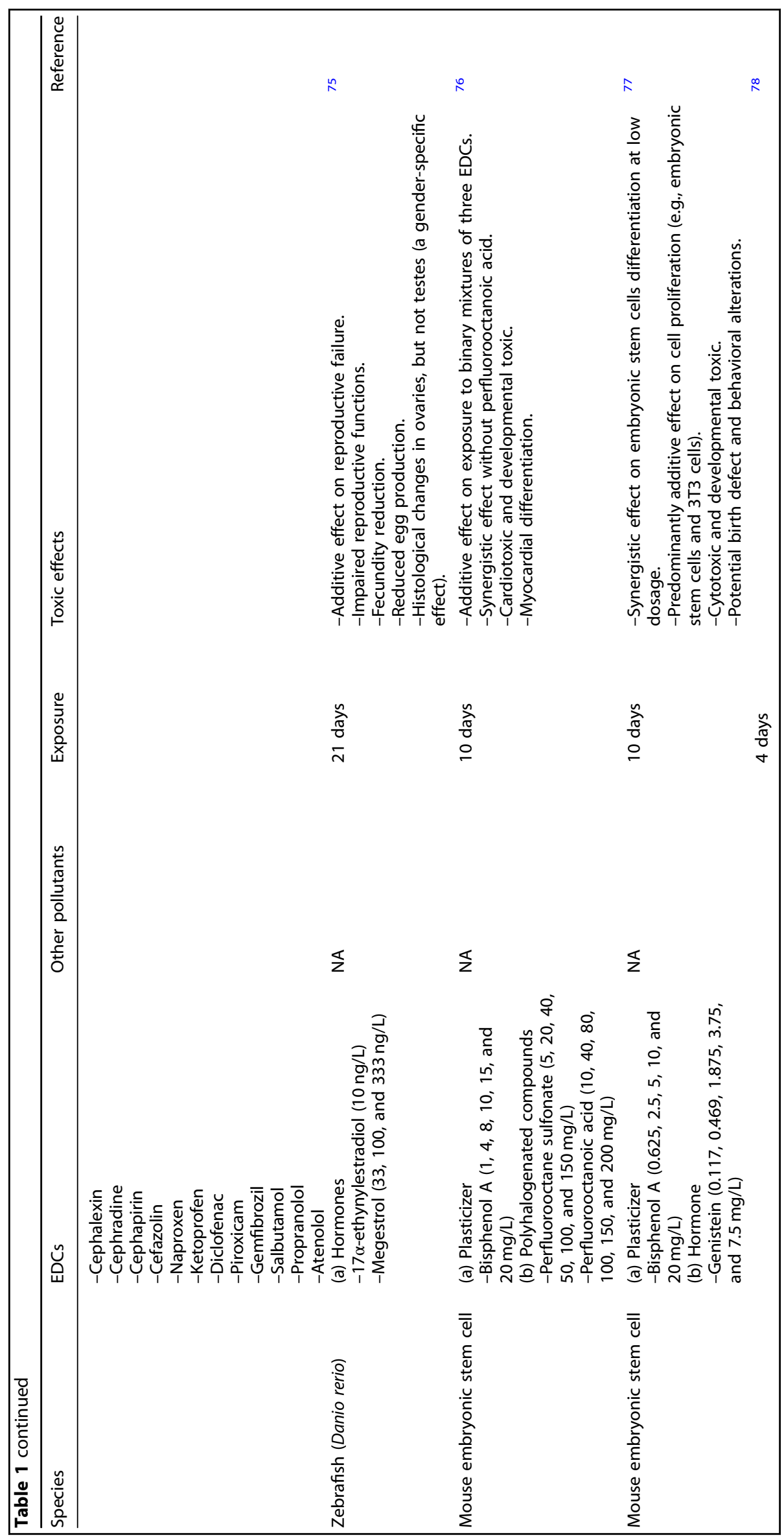


Table 2. Overview of selected studies on risk perception and decision making on different types of water

\begin{tabular}{|c|c|c|c|c|}
\hline Sample & Type of water & Dependent variables & Key explanatory variables & Reference \\
\hline $\begin{array}{l}\text { Toowoomba. Australia } \\
(N=401)\end{array}$ & (a) Recycled water & $\begin{array}{l}\text { (a) Perception } \\
\text {-General water quality } \\
\text { - Health risk } \\
\text { (b) Acceptance }\end{array}$ & $\begin{array}{l}\text {-Social trust (fairness, identity, and } \\
\text { credibility) }\end{array}$ & 47 \\
\hline Australia $(N=1000)$ & $\begin{array}{l}\text { (a) Desalinated water } \\
\text { (b) Recycled water }\end{array}$ & $\begin{array}{l}\text { (a) Perception } \\
\text {-Bacteria or viruses } \\
\text {-Disinfectants } \\
\text {-Endocrine disruptors } \\
\text {-Organoleptic properties } \\
\text { - Health risk } \\
\text { (b) Acceptance } \\
\text { (c) Comparison } \\
\text {-Tap water and bottled water quality }\end{array}$ & $\begin{array}{l}\text { - Knowledge } \\
\text { - Likelihood of use } \\
\text { - Socio-demographics }\end{array}$ & 43 \\
\hline $\begin{array}{l}\text { Western Newfoundland, } \\
\text { Canada }(N=100)\end{array}$ & (a) Tap water & $\begin{array}{l}\text { (a) Perception } \\
\text {-Water quality (organoleptic } \\
\text { properties) } \\
\text {-Health risk } \\
\text {-Practice } \\
\text { (b) Satisfaction } \\
\text {-Water quality } \\
\text {-Water service } \\
\text { (c) Association } \\
\text {-Perceived and actual water quality }\end{array}$ & -Socio-demographics & 14 \\
\hline United States $(N=632)$ & $\begin{array}{l}\text { (a) Tap water } \\
\text { (b) Bottled water }\end{array}$ & $\begin{array}{l}\text { (a) Perception } \\
\text {-Health risk } \\
\text { (b) Water use }\end{array}$ & $\begin{array}{l}\text {-Belief } \\
\text {-Experience } \\
\text {-Sources of information } \\
\text {-Socio-demographics }\end{array}$ & 52 \\
\hline $\begin{array}{l}\text { Switzerland and Germany } \\
(N=849)\end{array}$ & $\begin{array}{l}\text { (a) Tap water } \\
\text { (b) Bottled water }\end{array}$ & $\begin{array}{l}\text { (a) Consumption behavior/choice } \\
\text {-Tap water and bottled water }\end{array}$ & $\begin{array}{l}\text {-Social norms } \\
\text {-Affect } \\
\text {-Image (personal and water) } \\
\text {-Environmental concern } \\
\text {-Convenience }\end{array}$ & 42 \\
\hline $\begin{array}{l}\text { Kennebec County, Maine, } \\
\text { United States }(N=525)\end{array}$ & (a) Private well water & $\begin{array}{l}\text { (a) Water quality testing behavior } \\
\text { and treatment practices }\end{array}$ & $\begin{array}{l}\text {-Risk (vulnerability, severity, and } \\
\text { knowledge) } \\
\text {-Attitude (affective and } \\
\text { instrumental) } \\
\text {-Norm (descriptive, injunctive, and } \\
\text { personal) } \\
\text {-Ability (action knowledge and self- } \\
\text { efficacy) } \\
\text {-Self-regulation (action planning, } \\
\text { remembering, and commitment) }\end{array}$ & 12 \\
\hline
\end{tabular}




\begin{tabular}{|llll|}
\hline Table 2 continued & & & \\
\hline Sample & Type of water & Dependent variables & Key explanatory variables \\
\hline Bangladesh $(N=872)$ & & & -Intention to have water tested \\
& (a) Removal filters & (a) Drinking water behavior (habitual & -Secio-demographics \\
& (household and & use of arsenic-safe water options) & -Vulnerability \\
& community) & -Perceived habit & -Attitude (affective and \\
& (b) Household rainwater & -Automaticity & instrumental) \\
& harvesting & -Regularity & -Norm (descriptive and injunctive) \\
& (c) Rural piped water & & -Self-efficacy \\
& supply & & \\
& (d) Pond sand filters & & \\
& (e) Dug wells & & \\
& (f) Well-switching & & \\
\hline
\end{tabular}

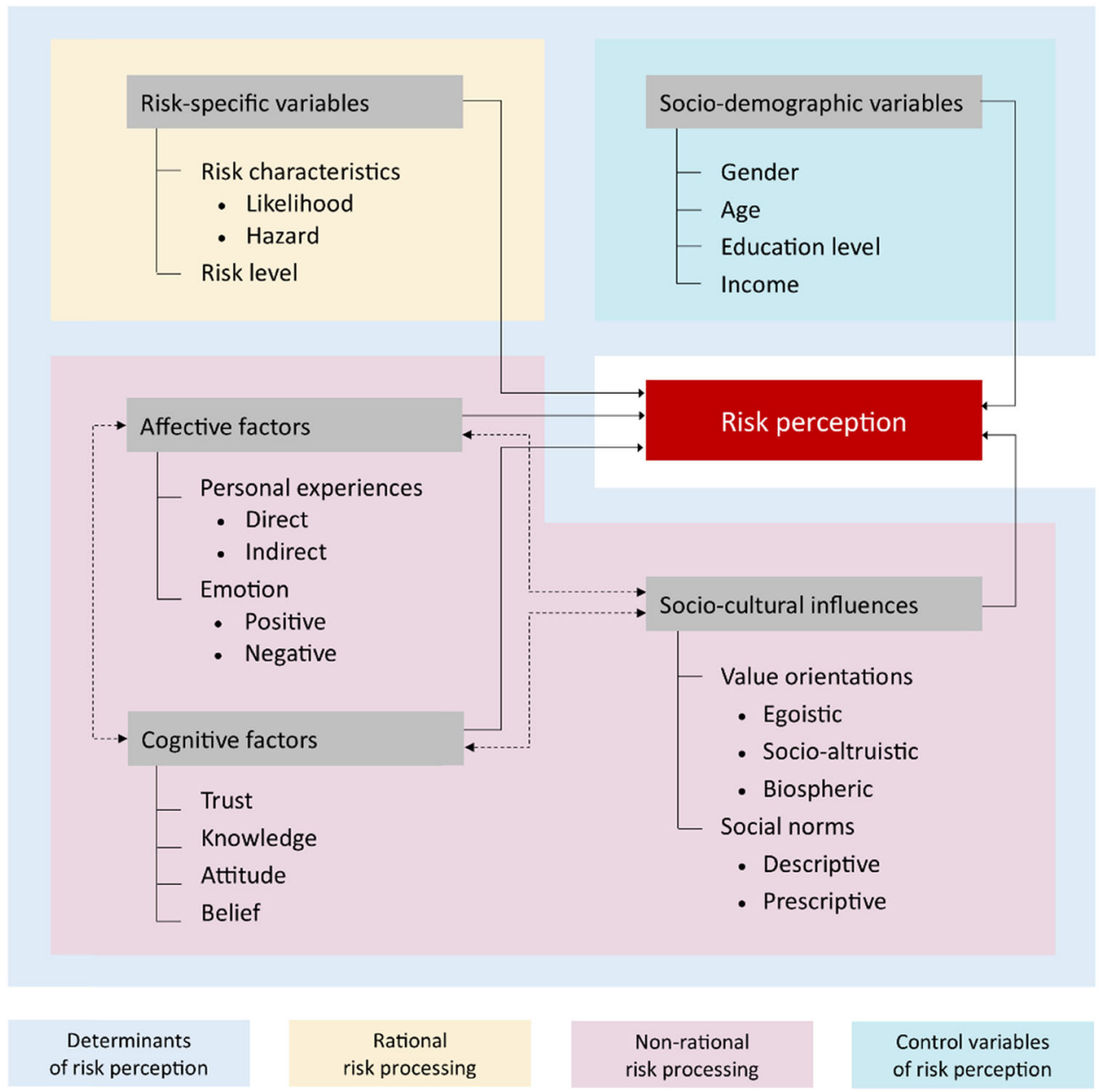

Fig. 4 Conceptual model of risk perception of environmental EDCs and drinking water quality. The interconnection among the different dimensions of risk perception depicts the importance of a theoretical understanding of how risk perceptions function in social systems for effective communication and risk management

drinking. ${ }^{43}$ Public acceptance and the willingness of the population to adopt alternative water resources and consider a range of applications have commonly been assessed based on knowledge of the environmental issues, health concerns, and the likelihood of using alternative water resources. In this context, willingness to pay is a risk outcome measure that is impacted by a risk behavior in compliance with perceived risk. ${ }^{44}$

Individuals depend on social trust when they have limited knowledge or a limited technical background to assess risks themselves, which is also aimed at reducing the complexity of an issue. ${ }^{45}$ Nonetheless, there are different dimensions of trust. Social trust reflects trust toward individuals in general or toward specific social groups (e.g., mass media and scientists/experts), whereas institutional trust represents the trustfulness of institutions functioning in a community (e.g., local authorities, governments, and nongovernment organizations). ${ }^{46}$ Depending on the situation, there are salient values underlying social trust, probably including competency. Trust in authorities influences attitudes toward public goods and services, in that individuals with greater trust are expected to feel more confident about the status of drinking 
water quality and believe in the decisions and capability of authorities in addressing any concerns. ${ }^{15,47-49}$ For example, individuals have a lower willingness to pay when they express greater distrust, on average, toward state and local government agencies. ${ }^{49}$ With the strong predictive power of trust in risk perception, greater levels of institutional trust have contributed to an increased willingness to pay for drinking water quality improvement and greater acceptance of recycled water schemes. ${ }^{15,46,47}$

Individuals exhibit risk behavior that is consistent with the belief that is formed based on the information they have, even though the process is always processed nonrationally (e.g., emotion and experience). ${ }^{50,51}$ Thus, beliefs in the likelihood and consequences of a hazard are predictive of risk perception. Subsequently, the beliefs produce attitudes, norms, intentions, and behaviors that are consistent with the beliefs. Additionally, beliefs about health, taste, water quality, lifestyle, the environment, and available alternatives have been observed to influence bottled water consumption, in that the belief strength varies significantly based on the rate of consumption. ${ }^{51}$ For example, consumers that exhibit high bottled water consumption have low intentions to reduce their consumption. Prior experiences and sources of information, the differences in beliefs and perceptions about water type (e.g., tap water and bottled water), location (e.g., home and work) and intended use (e.g., direct and indirect consumption) determine water use. ${ }^{43,51,52}$

Additionally, individual experiences potentially influence the choice of water resources, as risk perceptions and responses are sensitive to people's everyday lives and experiences, with direct experiences being more influential than indirect experiences. ${ }^{43,53}$ In addition, emotion resulting from previous experience affects trust and thus risk perception, with individuals with positive emotions having greater levels of trust and perceiving less risk than individuals with negative emotions. ${ }^{15}$ Cognitive responses increase with the level of impact.

Moreover, social trust, which accounts for one of the most important components of social capital, has a significant influence on social norms and social networks through the perception that other community members act through similar means for the common good with shared perceptions. ${ }^{42,46}$ In contrast, sociocultural factors determine cognitive processes and introduce affective reactions based on different types of knowledge and/or attitudes to generate risk perception because knowledge is built through cultural values, social norms, and local experiences. ${ }^{10}$ Additionally, the subsequent attitude resulting from direct experience (affective factor, i.e., experience) and media exposure (cognitive factor, i.e., social trust) is predictive of the willingness to pay for public safety. ${ }^{54}$ Furthermore, a strong association between a belief (self-efficacy), social norm (descriptive norm), and attitude (instrumental and affective attitude) toward a safe water option contributes to the likelihood of combining social-cognitive factors (modeling perspective) and considering incorporating these factors in communication (intervention perspective). ${ }^{12,55}$ The interconnection among the different dimensions of risk perception is illustrated in Fig. 4 and further explained below.

Risk perception is driven by sociocultural identity, particularly through variations in personal beliefs and the values shared with others (social identity) as well as beliefs in subjective norms (cultural identity). ${ }^{45}$ For example, in a previous study, the perceived hazards in China and the US in response to different risk contexts differed as a function of culture. ${ }^{56}$ Moreover, cultures (i.e., national, regional, organizational, and professional cultures) with societal and individual beliefs have influenced the implementation of water safety plans in urban water utilities. ${ }^{57}$ Additionally, a more reliable use of value orientations serves as a proxy for modeling cultural influences. In terms of environmental concern, value orientation is commonly classified into (i) egoistic values (i.e., personal basis), (ii) socio-altruistic values (i.e., basis of costs or benefits to human groups such as a community, ethnic group or all of humanity), and (iii) biospheric values (i.e., basis of costs or benefits to the ecosystem). ${ }^{58,59}$ Moreover, egoistic and altruistic values have positive impacts on promoting watersaving behavior, while biospheric values positively influence water consumption behavior. ${ }^{60}$ Biospheric values emphasize the social influences on environmental concern and are more strongly correlated with risk perception than egoistic and altruistic values. $^{59}$ As values act as guiding principles in life and the foundations of beliefs and behaviors, value orientation could be predictive of public risk perception and behavior regarding drinking water quality.

In addition, the tendency of an individual to comply with social norms (individuals act through similar means for the common belief in and good of the community) influences his/her tendency to pay for better drinking water quality. ${ }^{46}$ Descriptive norms describe common actions in a given situation (what most others do), whereas prescriptive norms refer to expected behavior that should be performed in a given situation (what most others approve or disapprove of.$^{61}$ In the context of social norms, descriptive and prescriptive norms (that are aligned and made salient) are important in ensuring positive changes in behavioral intention. ${ }^{62}$ In conclusion, the perception of the risks related to drinking water quality in regard to EDCs could be explained by a social-psychological model that combines and integrates cognitive, experiential, and sociocultural factors and that incorporates sociodemographic variables, which are discussed below.

\section{SOCIODEMOGRAPHIC VARIABLES IN RISK PROCESSING}

In addition, the actual or perceived proximity to a potential risk may differ by sociodemographic group, thus affecting the risk perception of drinking water quality (amplification or attenuation effects) because sociodemographic factors are associated with many life outcomes. For example, the influences are clearly observable when education determines the risk processing method and accelerates a positive risk outcome. ${ }^{12,39,49}$

Perceiving risks and making choices are different between age groups. For instance, older adults (aged 40-60 years) are more aware of and willing to consider the environmental hazards of consuming pharmaceuticals compared to younger adults (aged 20-39 years). ${ }^{34}$ Moreover, children have been observed to increase the salience of issues to parents (i.e., safe access to potable drinking water), thus leading to a higher willingness to pay for safe tap water. ${ }^{49}$ Apart from that observation, the social cognition of risk perception and behavior occurs and varies between individuals and across development. ${ }^{63} \mathrm{~A}$ significant development of social cognition has been observed during human adolescence, which is a life stage characterized by broad behavioral and environmental changes, while the social influence effects decreased with age.

Subsequently, several studies have emphasized the need to explore risk perception, risk behavior, decision making, and public satisfaction with regard to drinking water quality based on sociodemographic differences (i.e., age, gender, educational level, and income) (Table 2). Thus, knowing the demographic differences may help strategize communication by targeting communication materials to specific subgroups.

\section{SOLUTIONS TO ACCELERATE PUBLIC-PERCEIVED RISKS OF EDCS IN DRINKING WATER: RISK COMMUNICATION AND GOVERNANCE}

Other than preventive measures during the monitoring and management of a drinking water supply system to reduce human exposure to the risks associated with EDCs in drinking water (Fig. 3), effective communication and governance are required to promote risk mitigation through improved quantitative understanding, 


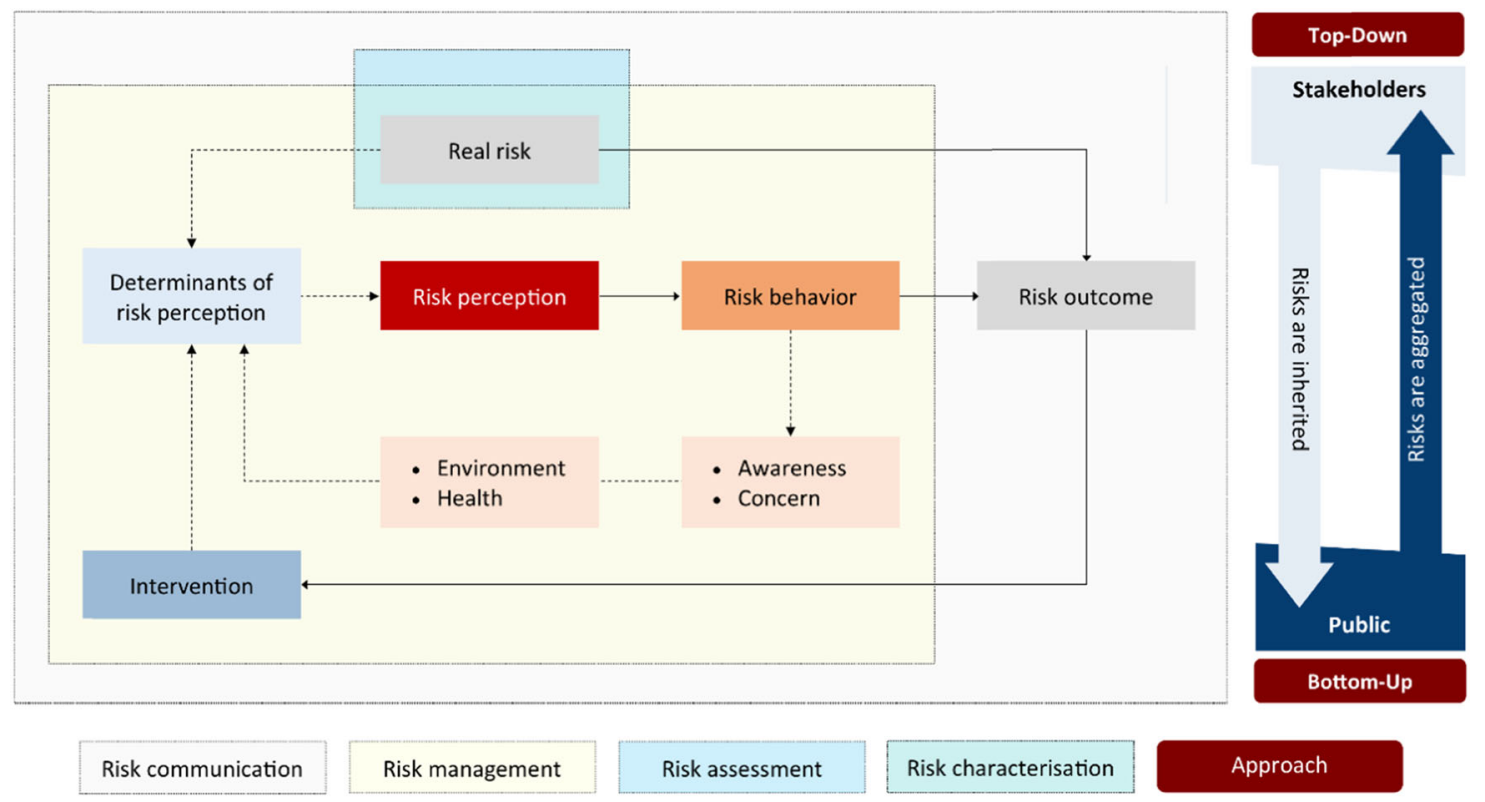

Fig. 5 Risk governance network to identify the pubic-perceived risks of EDCs in the environment and drinking water for developing risk preparedness and risk mitigation behavior. Community-based risk governance with two-way interactive communication, involving a a topdown approach (directs attention towards or away from risk) and $\mathbf{b}$ a bottom-up approach (creates salient values in risk processing)

accurate arithmetic judgments, and enhanced behavioral changes. Interventions are implied as essential in improving the perceived risks associated with drinking water quality for the development of risk preparedness and risk mitigation behavior; thus, monitoring and regulating possible EDC contamination in drinking water supply to ensure safe access to potable water are essential as well (Fig. 5). The solution is expected to be applicable for filling the knowledge gaps in the occurrence of EDCs in drinking water and the associated health risks. In this context, top-down and bottom-up approaches demonstrate support for community-based risk governance with two-way interactive communication, whereby both approaches have the same goals in managing the associated risks and improving risk perception via different paths. The top-down approach (multiple stakeholders, such as the government, that frequently initiate the formulation of the vision for future directions) directs (shifts or maintains) attention toward or away from risk. Simultaneously, the bottom-up approach (public, i.e., community that often develops and experiments with new approaches to meet the challenges as they view them) creates salient values in risk processing. Thus, the two-directional approach contributes to a combination of current scientific knowledge and policy analysis (top-down collected knowledge) and local knowledge, experiences, and perceptions (bottom-up information gathered via public observations). For example, the environmental policy and governance decision-making process requires not only involvement from multiple stakeholders but also public participation, whereby the public subsequently becomes another specific stakeholder. Meanwhile, all relevant information must be made accessible, and sufficient attention should be paid to the public during decision making. Nevertheless, the balance between the two-directional approach of governing is highly challenging for sustainable governance.

Local and social networks (i.e., neighborhood networks, media or government messaging) are keys to circulating knowledge of risks and translate risk knowledge into routine water testing behaviors. ${ }^{10,60}$ When individuals adopt the behaviors or attitudes of others whom they communicate with in a social network, social contagion of risk perception and behavior develops in this dynamic social network, depending on the interpersonal networks. ${ }^{64}$ Furthermore, stronger and more frequent contagion affects the interactions between experts and laypeople (expert-tolayperson) more than those interactions among experts (expertto-expert) alone or only between laypeople (layperson-to-layperson). ${ }^{65} \mathrm{~A}$ better theoretical understanding of how risk perceptions function in social systems contributes to effective communication, which is essential to risk management. The impacts are clearly applied in the two-directional orientation of communication and governance.

However, selecting the most appropriate risk communication device to be used is an important aspect of communicating a change in risk. Certainly, there is reduced effectiveness in communicating risks and maintaining trustworthiness and credibility by means of dry presentations of analytical facts, especially when individuals process information experientially. ${ }^{40}$ Typically, visualization (i.e., graphical aid) is a beneficial method for communicating health risks, as the design of graphics strongly influences perception. ${ }^{66}$ The risk ladder, a commonly applied visual aid, has been proposed as more effective than a square grid because risk ladders increase the understanding of a risk by providing clear and useful information. ${ }^{67}$ For instance, a risk ladder affects choice behavior and increases the willingness to pay for reducing the environmental or health risks of micropollutants. ${ }^{68}$

\section{CONCLUSION AND RECOMMENDATION}

Because environmental EDCs exhibit (i) ubiquitous occurrences in the water cycle (wastewater-aquatic system-drinking water), (ii) challenges in removal efficiency, cost effectiveness, and sustainable development for the whole treatment and remediation system, and (iii) profound effects on the environment, public health, and the economy, policy makers (e.g., local authorities, regional authorities, and the provincial government) have a mandatory responsibility to establish legislative regulations to protect a nation's water resources. The current negligible risks of drinking water might not have a substantial impact on human health, but long-term exposure (accumulation of EDCs as low as $\mathrm{ng} / \mathrm{L}$ to $\mathrm{mg} / \mathrm{L}$ and the combined effects of EDC mixtures) could contribute to the significant health risks. EDC occurrence in the drinking water supply and the potential health risks associated with EDCs via drinking water consumption should not be 


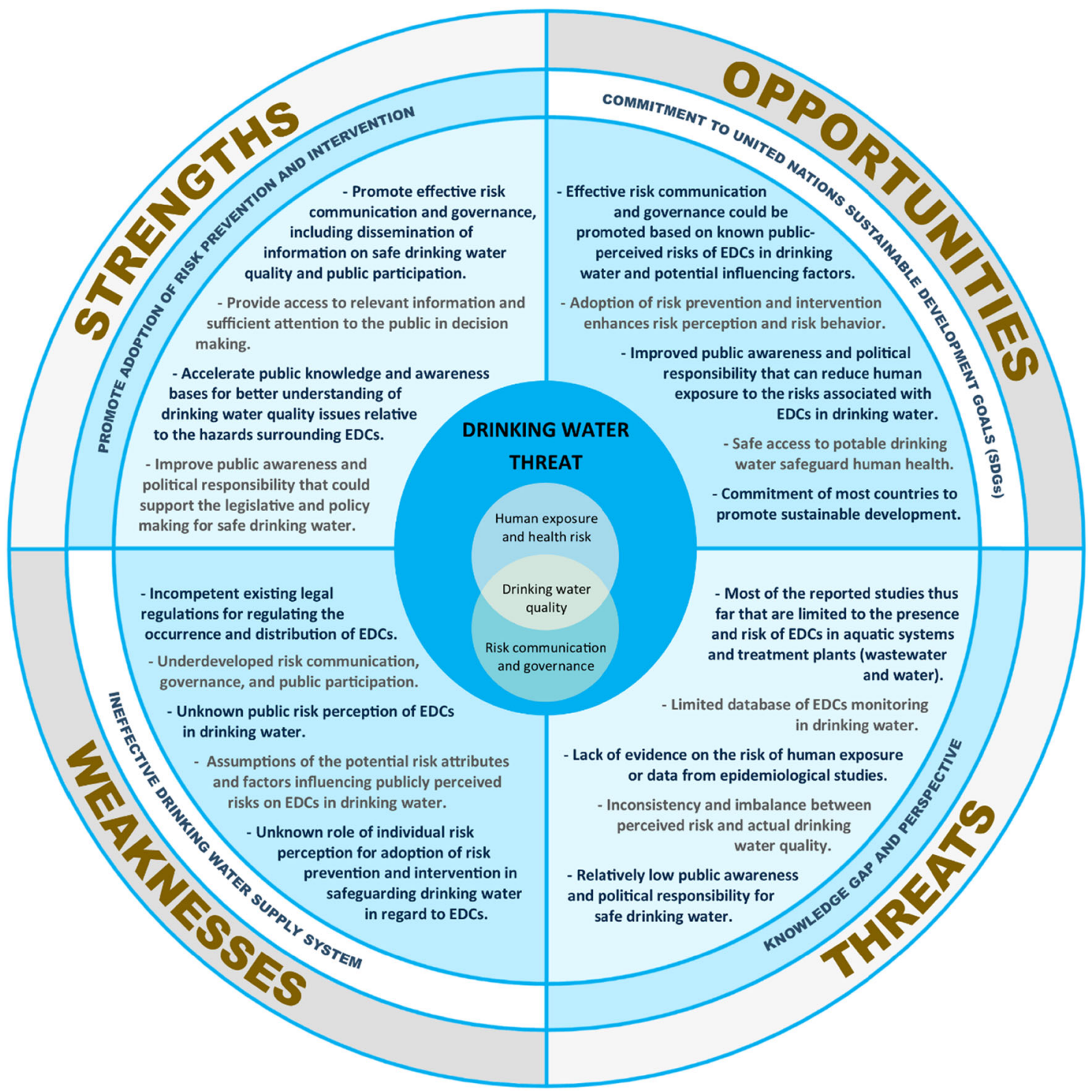

Fig. 6 Strengths, weaknesses, opportunities, and threats (SWOT) analysis of drinking water threats as the way forward for safe drinking water, formulating the need for preventive and intervention measures for a a better understanding of the nature and extent of EDCs in the drinking water supply system, $\mathbf{b}$ adequate regulatory efforts and communication, $\mathbf{c}$ effective dissemination of information on safe drinking water, and $\mathbf{d}$ active public involvement

neglected since EDC monitoring in drinking water is limited and evidence of the risk of human exposure and data from epidemiological studies are underdeveloped. However, one cannot say there are no potential risks of EDC consumption via daily drinking water intake; thus, the potential risks and knowledge gaps should be urgently evaluated to confirm or disprove this. Apparently, scientific efforts are solely required to fill this knowledge gap to ensure safe access to drinking water. These efforts concern not only the scientific community but also the public, thus challenging the adoption of preventive and mitigation measures in regulating EDCs in drinking water. This aspect is a challenge for the scientific community that works on evidence/ data in nature and the extent of contact with EDCs; thus, the public is not expected to demonstrate good risk behavior (e.g., awareness and concern) and participation.

The strengths, weaknesses, opportunities, and threats (SWOT) analysis (Fig. 6) depicts the idea of (i) revisiting drinking water quality from the perspective of potential EDC exposure and human health risks and (ii) introducing risk communication and governance prior to safe access to drinking water. There is a need to build a basis of public knowledge and awareness to reach a better understanding of the issues related to drinking water quality relative to the hazards surrounding EDCs, which is the way forward for safe drinking water. Throughout community-based risk governance with two-way interactive communication, improved public awareness and political responsibility could support legislative and policy making for safe drinking water. Overall, an in-depth focus on the public-perceived risks of EDCs in drinking water and the potential factors influencing the risk perceptions of a population are required to understand the public risk perceptions of human exposure and the associated health risks. It is also important to capture the complex dynamic of the public in perceiving risks for effective communication and governance, including the dissemination of information on safe drinking water quality and public participation in regard to EDCs.

Currently, revisiting drinking water quality with preventive and intervention measures should be prioritized to prevent the scenario of "drinking the undrinkable". Providing a comprehensive understanding of the nature and extent of EDCs in the drinking water supply system, governing regulatory efforts and 
communication, disseminating information on safe drinking water, and giving the public the right to a voice in decision making are universally relevant and peremptory to all countries for regulating EDCs in drinking water supply systems and minimizing the associated health risks. Nonetheless, these concerns should be given toward the drinking water quality as a whole, not merely the emerging issue of EDC contamination in tap water. After all, the potential supply of EDC-containing tap water requires much more attention as their presence is not publicly known.

\section{ACKNOWLEDGEMENTS}

This work was supported by Universiti Putra Malaysia (UPM) under Geran PutraInisiatif Putra Siswazah [GP-IPS/2017/9574600] and the Ministry of Education (MOE) under Trans-Disciplinary Research Grant Scheme [TRGS/2016/5535710]. S.Y.W. would also like to acknowledge the Graduate Research Fellowship (GRF) awarded by UPM.

\section{AUTHOR CONTRIBUTIONS}

All authors contributed to the initial conceptualization of the work. All authors contributed substantively to the final written version and agreed with its content.

\section{ADDITIONAL INFORMATION}

Competing interests: The authors declare no competing interests.

Publisher's note: Springer Nature remains neutral with regard to jurisdictional claims in published maps and institutional affiliations.

\section{REFERENCES}

1. Daughton, C. G. Pharmaceuticals and the Environment (PiE): Evolution and impact of the published literature revealed by bibliometric analysis. Sci. Total Environ. 562, 391-426 (2016).

2. Barber, L. B., Loyo-Rosales, J. E., Rice, C. P., Minarik, T. A. \& Oskouie, A. K. Endocrine disrupting alkylphenolic chemicals and other contaminants in wastewater treatment plant effluents, urban streams, and fish in the Great Lakes and Upper Mississippi River regions. Sci. Total Environ. 517, 195-206 (2015).

3. Liu, Y. H. et al. Occurrence, distribution and risk assessment of suspected endocrine-disrupting chemicals in surface water and suspended particulate matter of Yangtze River (Nanjing section). Ecotoxicol. Environ. Saf. 135, 90-97 (2017)

4. Omar, T. F. T., Aris, A. Z., Yusoff, F. M. \& Mustafa, S. Occurrence, distribution, and sources of emerging organic contaminants in tropical coastal sediments of anthropogenically impacted Klang River estuary, Malaysia. Mar. Pollut. Bull. 131, 284-293 (2018)

5. Padhye, L. P., Yao, H., Kung'u, F. T. \& Huang, C. H. Year-long evaluation on the occurrence and fate of pharmaceuticals, personal care products, and endocrine disrupting chemicals in an urban drinking water treatment plant. Water Res. 51 266-276 (2014).

6. Wee, S. Y. \& Aris, A. Z. Endocrine disrupting compounds in drinking water supply system and human health risk implication. Env. Int. 106, 207-233 (2017).

7. Lee, S., Jeong, W., Kannan, K. \& Moon, H. B. Occurrence and exposure assessment of organophosphate flame retardants (OPFRs) through the consumption of drinking water in Korea. Water Res. 103, 182-188 (2016).

8. Yang, G. C., Yen, C. H. \& Wang, C. L. Monitoring and removal of residual phthalate esters and pharmaceuticals in the drinking water of Kaohsiung City, Taiwan. J. Hazard. Mater. 277, 53-61 (2014).

9. Boleda, M. R., Huerta-Fontela, M., Ventura, F. \& Galceran, M. T. Evaluation of the presence of drugs of abuse in tap waters. Chemosphere 84, 1601-1607 (2011).

10. Chappells, $\mathrm{H}$. et al. Arsenic in private drinking water wells: an assessment of jurisdictional regulations and guidelines for risk remediation in North America. J. Water Health 12, 372-392 (2014).

11. Chowdhury, S., Mazumder, M. J., Al-Attas, O. \& Husain, T. Heavy metals in drinking water: Occurrences, implications, and future needs in developing countries. Sci. Total Environ. 569, 476-488 (2016).

12. Flanagan, S. V., Marvinney, R. G. \& Zheng, Y. Influences on domestic well water testing behavior in a Central Maine area with frequent groundwater arsenic occurrence. Sci. Total Environ. 505, 1274-1281 (2015).

13. WHO. Pharmaceuticals in Drinking-water (World Health Organization, Geneva, 2011).
14. Ochoo, B., Valcour, J. \& Sarkar, A. Association between perceptions of public drinking water quality and actual drinking water quality: a community-based exploratory study in Newfoundland (Canada). Environ. Res. 159, 435-443 (2017).

15. Wachinger, G., Renn, O., Begg, C. \& Kuhlicke, C. The risk perception paradoximplications for governance and communication of natural hazards. Risk Anal. 33, 1049-1065 (2013).

16. Martin, W. E., Martin, I. M. \& Kent, B. The role of risk perceptions in the risk mitigation process: the case of wildfire in high risk communities. J. Environ. Manag. 91, 489-498 (2009).

17. Azzouz, A., Rascón, A. J. \& Ballesteros, E. Simultaneous determination of parabens, alkylphenols, phenylphenols, bisphenol $\mathrm{A}$ and triclosan in human urine, blood and breast milk by continuous solid-phase extraction and gas chromatography-mass spectrometry. J. Pharm. Biomed. Anal. 119, 16-26 (2016).

18. Faniband, M., Lindh, C. H. \& Jönsson, B. A. Human biological monitoring of suspected endocrine-disrupting compounds. Asian J. Androl. 16, 5-16 (2014).

19. Shekhar, S. et al. Detection of phenolic endocrine disrupting chemicals (EDCs) from maternal blood plasma and amniotic fluid in Indian population. Gen. Comp. Endocrinol. 241, 100-107 (2017).

20. Aris, A. Z., Shamsuddin, A. S. \& Praveena, S. M. Occurrence of 17a-ethynylestradiol (EE2) in the environment and effect on exposed biota: a review. Environ. Int. 69, 104-119 (2014).

21. Simazaki, D. et al. Occurrence of selected pharmaceuticals at drinking water purification plants in Japan and implications for human health. Water Res. 76 187-200 (2015).

22. Leung, H. W. et al. Pharmaceuticals in tap water: human health risk assessment and proposed monitoring framework in China. Environ. Health Perspect. 121, 839-846 (2013).

23. Li, X., Ying, G. G., Su, H. C., Yang, X. B. \& Wang, L. Simultaneous determination and assessment of 4-nonylphenol, bisphenol $A$ and triclosan in tap water, bottled water and baby bottles. Environ. Int. 36, 557-562 (2010).

24. US EPA. Exposure Factors Handbook 2011 Edition (Final) (United States Environmental Protection Agency, Washington, DC, 2014).

25. Bardosono, S. et al. Fluid intake of pregnant and breastfeeding women in Indonesia: a cross-sectional survey with a seven-day fluid specific record. Nutrients 8, 651 (2016).

26. Houtman, C. J., Kroesbergen, J., Lekkerkerker-Teunissen, K. \& van der Hoek, J. P. Human health risk assessment of the mixture of pharmaceuticals in Dutch drinking water and its sources based on frequent monitoring data. Sci. Total Environ. 496, 54-62 (2014).

27. Giulivo, M., de Alda, M. L., Capri, E. \& Barceló, D. Human exposure to endocrine disrupting compounds: Their role in reproductive systems, metabolic syndrome and breast cancer: a review. Environ. Res. 151, 251-264 (2016).

28. Sifakis, S., Androutsopoulos, V. P., Tsatsakis, A. M. \& Spandidos, D. A. Human exposure to endocrine disrupting chemicals: effects on the male and female reproductive systems. Environ. Toxicol. Pharmacol. 51, 56-70 (2017).

29. Di Donato, M. et al. Recent advances on bisphenol-A and endocrine disruptor effects on human prostate cancer. Mol. Cell Endocrinol. 457, 35-42 (2017).

30. Rosenfeld, C. S. Bisphenol A and phthalate endocrine disruption of parental and social behaviors. Front. Neurosci. 9, 57 (2015).

31. Tapia-Orozco, N. et al. Environmental epigenomics: current approaches to assess epigenetic effects of endocrine disrupting compounds (EDC's) on human health. Environ. Toxicol. Pharmacol. 51, 94-99 (2017).

32. Kabir, E. R., Rahman, M. S. \& Rahman, I. A review on endocrine disruptors and their possible impacts on human health. Environ. Toxicol. Pharmacol. 40, 241-258 (2015).

33. Jiang, X. et al. Low-dose and combined effects of oral exposure to bisphenol A and diethylstilbestrol on the male reproductive system in adult Sprague-Dawley rats. Environ. Toxicol. Pharmacol. 43, 94-102 (2016).

34. Dohle, S., Campbell, V. E. \& Arvai, J. L. Consumer-perceived risks and choices about pharmaceuticals in the environment: a cross-sectional study. Environ. Health 12, 45 (2013).

35. Jallow, M. F. A., Awadh, D. G., Albaho, M. S., Devi, V. Y. \& Thomas, B. M. Pesticide risk behaviors and factors influencing pesticide use among farmers in Kuwait. Sci. Total Environ. 574, 490-498 (2017).

36. Rezaei, R., Damalas, C. A. \& Abdollahzadeh, G. Understanding farmers' safety behavior toward pesticide exposure and other occupational risks: the case of Zanjan, Iran. Sci. Total Environ. 616, 1190-1198 (2018).

37. Vellinga, A. et al. Public practice regarding disposal of unused medicines in Ireland. Sci. Total Environ. 478, 98-102 (2014).

38. Yeh, J. C. \& Liao, C. H. Assessment of perception and intention in pesticide purchase in Taiwan. Environ. Monit. Assess. 188, 275 (2016).

39. Janmaimool, P. \& Watanabe, T. Evaluating determinants of environmental risk perception for risk management in contaminated sites. Int. J. Environ. Res. Publ. Health 11, 6291-6313 (2014). 
40. Carlton, S. J. \& Jacobson, S. K. Climate change and coastal environmental risk perceptions in Florida. J. Environ. Manag. 130, 32-39 (2013).

41. Risk Management Standard (AS/NZS 4360:2004) (Standards Australia, 2004).

42. Etale, A., Jobin, M. \& Siegrist, M. Tap versus bottled water consumption: the influence of social norms, affect and image on consumer choice. Appetite 121, 138-146 (2018).

43. Dolnicar, S. \& Schäfer, A. I. Desalinated versus recycled water: public perceptions and profiles of the accepters. J. Environ. Manag. 90, 888-900 (2009).

44. Dealy, B. C., Horn, B. P., Bohara, A. K., Berrens, R. P. \& Bryan, A. D. The impact of behavioral risk-reduction interventions on willingness to pay to avoid sexually transmitted infections: a stated preference study of justice-involved youth. Appl. Econ. 49, 1-13 (2017).

45. Dobbie, M. F. \& Brown, R. R. A framework for understanding risk perception, explored from the perspective of the water practitioner. Risk Anal. 34, 294-308 (2014).

46. Polyzou, E., Jones, N., Evangelinos, K. I. \& Halvadakis, C. P. Willingness to pay for drinking water quality improvement and the influence of social capital. J. SocioEcon. 40, 74-80 (2011).

47. Ross, V. L., Fielding, K. S. \& Louis, W. R. Social trust, risk perceptions and public acceptance of recycled water: testing a social-psychological model. J. Environ. Manag. 137, 61-68 (2014).

48. Alexander, K. S. et al. Community Perceptions of Risk, Trust and Fairness in Relation to the Indirect Potable Use of Purified Recycled Water in South East Queensland: A Scoping Report Urban Water Security Research Alliance Technical Report No. 2. Urban Water Security Research Alliance: Queensland (2008).

49. Chatterjee, C., Triplett, R., Johnson, C. K. \& Ahmed, P. Willingness to pay for safe drinking water: A contingent valuation study in Jacksonville, FL. J. Environ. Manag. 203, 413-421 (2017).

50. Ajzen, I. The theory of planned behavior: reactions and reflections. Psychol. Health 26, 1113-1127 (2011)

51. van der Linden, S. Exploring beliefs about bottled water and intentions to reduce consumption: The dual-effect of social norm activation and persuasive information. Environ. Behav. 47, 526-550 (2013).

52. Gorelick, M. H. et al. Perceptions about water and increased use of bottled water in minority children. Arch. Pediatr. Adolesc. Med. 165, 928-932 (2011).

53. Viscusi, W. K. \& Zeckhauser, R. J. The relative weights of direct and indirect experiences in the formation of environmental risk beliefs. Risk Anal. 35, 318-331 (2015).

54. Donahue, A. K. \& Miller, J. M. Experience, attitudes, and willingness to pay for public safety. Am. Rev. Public Adm. 36, 395-418 (2006).

55. Inauen, J., Tobias, R. \& Mosler, H. J. Predicting water consumption habits for seven arsenic-safe water options in Bangladesh. BMC Public Health 13, 417 (2013).

56. Lesch, M. F., Rau, P. L. P. \& Choi, Y. Effects of culture (China vs. US) and task on perceived hazard: Evidence from product ratings, label ratings, and product to label matching. Appl. Ergon. 52, 43-53 (2016).

57. Omar, Y. Y., Parker, A., Smith, J. A. \& Pollard, S. J. Risk management for drinking water safety in low and middle income countries-cultural influences on water safety plan (WSP) implementation in urban water utilities. Sci. Total Environ. 576, 895-906 (2017).

58. Stern, P. C. \& Dietz, T. The value basis of environmental concern. J. Soc. 50, 65-84 (1994).

59. van der Linden, S. The social-psychological determinants of climate change risk perceptions: Toward a comprehensive model. J. Environ. Psychol. 41, 112-124 (2015).

60. Aprile, M. C. \& Fiorillo, D. Water conservation behavior and environmental concerns: evidence from a representative sample of Italian individuals. J. Clean. Prod. 159, 119-129 (2017)

61. Cialdini, R. B., Reno, R. R. \& Kallgren, C. A. A focus theory of normative conduct: recycling the concept of norms to reduce littering in public places. J. Pers. Soc. Psychol. 58, 1015-1026 (1990).

62. Smith, J. R. et al. Congruent or conflicted? The impact of injunctive and descriptive norms on environmental intentions. J. Environ. Psychol. 32, 353-361 (2012).

63. Kilford, E. J., Garrett, E. \& Blakemore, S. J. The development of social cognition in adolescence: An integrated perspective. Neurosci. Biobehav. Rev. 70, 106-120 (2016).

64. Scherer, C. W. \& Cho, H. A social network contagion theory of risk perception. Risk Anal. 23, 261-267 (2003)

65. Muter, B. A., Gore, M. L. \& Riley, S. J. Social contagion of risk perceptions in environmental management networks. Risk Anal. 33, 1489-1499 (2013).

66. Garcia-Retamero, R. \& Cokely, E. T. Communicating health risks with visual aids. Curr. Dir. Psychol. Sci. 22, 392-399 (2013).
67. Botzen W. J. W., van den Bergh J. C. J. M. \& Aerts J. C. J. H. Report on a survey about perceptions of flood risk, willingness to pay for flood insurance, and willingness to undertake mitigation measures: explanation of the survey instrument. VU University Amsterdam. http://ivm45.ivm.vu.nl/adaptation/project/files/ File/NCIP/Botzen\%20vdBergh\%0Aerts-Report\%20Survey\%20perc\%20flood\% 20risk.pdf (2008), Accessed on 8 Aug 2016.

68. Logar, I. \& Brouwer, R. The effect of risk communication on choice behavior, welfare estimates and choice certainty. Water Resour. Econ. 18, 34-50 (2016).

69. Laetz, C. A., Baldwin, D. H., Hebert, V. R., Stark, J. D. \& Scholz, N. L. Elevated temperatures increase the toxicity of pesticide mixtures to juvenile coho salmon. Aquat. Toxicol. 146, 38-44 (2014).

70. Rehman, H. et al. Additive toxic effect of deltamethrin and cadmium on hepatic, hematological, and immunological parameters in mice. Toxicol. Ind. Health 33, 495-502 (2017).

71. Gonzalez-Rey, M., Mattos, J. J., Piazza, C. E., Bainy, A. C. D. \& Bebianno, M. J. Effects of active pharmaceutical ingredients mixtures in mussel Mytilus galloprovincialis. Aquat. Toxicol. 153, 12-26 (2014).

72. Li, Z., Lu, G., Yang, X. \& Wang, C. Single and combined effects of selected pharmaceuticals at sublethal concentrations on multiple biomarkers in Carassius auratus. Ecotoxicology 21, 353-361 (2012).

73. Almeida, Â. et al. Comparison of the toxicological impacts of carbamazepine and a mixture of its photodegradation products in Scrobicularia plana. J. Hazard Mater. 323, 220-232 (2017).

74. Li, S. W. \& Lin, A. Y. C. Increased acute toxicity to fish caused by pharmaceuticals in hospital effluents in a pharmaceutical mixture and after solar irradiation. Chemosphere 139, 190-196 (2015).

75. Hua, J., Han, J., Wang, X., Guo, Y. \& Zhou, B. The binary mixtures of megestrol acetate and 17 a-ethynylestradiol adversely affect zebrafish reproduction. Environ. Pollut. 213, 776-784 (2016).

76. Zhou, R. et al. Interactions between three typical endocrine-disrupting chemicals (EDCs) in binary mixtures exposure on myocardial differentiation of mouse embryonic stem cell. Chemosphere 178, 378-383 (2017).

77. Kong, D. et al. Individual and combined developmental toxicity assessment of bisphenol $A$ and genistein using the embryonic stem cell test in vitro. Food Chem. Toxicol. 60, 497-505 (2013).

78. Feng, M. et al. Evaluation of single and joint toxicity of perfluorooctane sulfonate, perfluorooctanoic acid, and copper to Carassius auratus using oxidative stress biomarkers. Aquat. Toxicol. 161, 108-116 (2015).

79. Hu, Y. et al. Antagonistic effects of a mixture of low-dose nonylphenol and di-nbutyl phthalate (monobutyl phthalate) on the Sertoli cells and serum reproductive hormones in prepubertal male rats in vitro and in vivo. PloS One 9, e93425 (2014).

80. Ab Razak, N. H., Praveena, S. M., Aris, A. Z. \& Hashim, Z. Quality of Kelantan drinking water and knowledge, attitude and practice among the population of Pasir Mas, Malaysia. Public Health 131, 103-111 (2016).

81. Hu, Z., Morton, L. W. \& Mahler, R. L. Bottled water: United States consumers and their perceptions of water quality. Int. J. Environ. Res. Public Health 8, 565-578 (2011).

82. Levêque, J. G. \& Burns, R. C. Predicting water filter and bottled water use in Appalachia: a community-scale case study. J. Water Health 15, 451-461 (2017).

83. McLeod, L., Bharadwaj, L. \& Waldner, C. Risk factors associated with the choice to drink bottled water and tap water in rural Saskatchewan. Int. J. Environ. Res. Publ. Health 11, 1626-1646 (2014).

Open Access This article is licensed under a Creative Commons Attribution 4.0 International License, which permits use, sharing, adaptation, distribution and reproduction in any medium or format, as long as you give appropriate credit to the original author(s) and the source, provide a link to the Creative Commons license, and indicate if changes were made. The images or other third party material in this article are included in the article's Creative Commons license, unless indicated otherwise in a credit line to the material. If material is not included in the article's Creative Commons license and your intended use is not permitted by statutory regulation or exceeds the permitted use, you will need to obtain permission directly from the copyright holder. To view a copy of this license, visit http://creativecommons. org/licenses/by/4.0/.

(c) The Author(s) 2019 